\title{
额尔古纳地块北缘早古生代后碰撞花岗岩的发现 及其地质意义
}

\author{
武 广(1) 孙丰月 ${ }^{(1)}$ 赵财胜 $^{(3}$ 李之䑣 ${ }^{(1}$ 赵爱琳 $^{(2}$ 庞庆帮 ${ }^{(2}$ 李广远 ${ }^{(2)}$ \\ (1)吉林大学地球科学学院, 长春 130026; (2)沈阳地质矿产研究所, 沈阳 110032; (3)矿产资源研究所, 北京 100037. \\ E-mail: sywguang@cgs.gov.cn)
}

\begin{abstract}
摘要 漠河县洛古河岩体主要岩石类型为二长花岗岩、石英闪长岩和花岗闪长岩, 另有少量的闪长岩、 英云闪长岩、石英二长闪长岩、石英二长岩、正长花岗岩及碱长花岗岩, 属高钾钙碱性岩系, 分为石英 闪长岩和二长花岗岩 2 个单元. 石英闪长岩单元 $\mathrm{SiO}_{2}$ 含量介于 $54.79 \% \sim 58.30 \%$ 之间, $\mathrm{Na}_{2} \mathrm{O} / \mathrm{CaO}$ 为 $0.79 \sim 1.53$, Shand 指数介于 $0.77 \sim 0.82$ 之间, 为准铝质岩石; 二长花岗岩单元 $\mathrm{SiO}_{2}$ 含量介于 $65.29 \% \sim 66.45 \%$ 之间, $\mathrm{Na}_{2} \mathrm{O} / \mathrm{CaO}$ 为 $1.73 \sim 3.43$, Shand 指数多数 $<1.05$, 为弱过铝质岩石. 稀土元素总量为 $180.18 \sim 344.32 \mu \mathrm{g} / \mathrm{g}$, 具 $\mathrm{Eu}$ 负异常 $(0.33 \sim 0.82)$, 稀土元素分馏不明显 $(\mathrm{La} / \mathrm{Yb})_{\mathrm{N}}$ 介于 4.12 10.45), 稀土配 分曲线为轻稀土富集型. 富集 $\mathrm{Rb}, \mathrm{Th}, \mathrm{U}, \mathrm{K}, \mathrm{La}, \mathrm{Ce}, \mathrm{Nd}, \mathrm{Hf}, \mathrm{Zr}$ 和 $\mathrm{Sm}$ 等元素, 而强烈亏损 $\mathrm{Ba}, \mathrm{Nb}, \mathrm{Ta}, \mathrm{Sr}$, $\mathrm{P}$ 和 $\mathrm{Ti}$ 等元素. 其主量元素、稀土元素和微量元素特征表明, 洛古河岩体形成于挤压体制向拉张体制转 换的构造环境, 属后碰撞花岗岩类. 石英闪长岩单元和二长花岗岩单元的 SHRIMP 锆石 U-Pb 年龄分别 为 $517 \pm 9$ 和 $504 \pm 8 \mathrm{Ma}$. 额尔古纳地块北缘早古生代后碰撞花岗岩的发现, 标志着萨拉伊尔运动结束 于 $500 \mathrm{Ma}$ 左右，表明位于额尔古纳地块与西伯利亚板块之间的古亚洲洋北支在早古生代期间已经封闭， 完成了古亚洲洋北洋的演化历史.
\end{abstract}

关键词 后碰撞花岗岩 SHRIMP U-Pb 年龄 早古生代 地球化学 额尔古纳地块

额尔古纳地块呈北东向延伸, 长达 $1500 \mathrm{~km}$ 以上, 是中亚-蒙古-兴安巨型复合造山带内的重要大地构 造单元. 该地块北侧为中生代蒙古-鄂霍茨克褶皱带; 西南缘被晚古生代南蒙古海洋沉积物所覆盖; 地块 的东北部与莫梅恩(马门)地块相连; 东南部以天山南蒙古-大兴安岭晚古生代缝合带为界与松嫩地块、 布列亚-佳木斯复合地块相邻, 并被晚古生代 中生代 岩浆作用所彻底改造 ${ }^{[1-5]}$. 关于额尔古纳地块的性 质、古亚洲洋及兴-蒙造山带演化历史等重大基础问 题, 一直是国内外地质界关注的重点之一, 也是长期 以来一直没有解决的问题. 20 世纪 80 年代以前至 80 年代初, 在槽台-多旋回理论的指导下, 认为本区是 加里东地槽褶皱带 ${ }^{[6,7]}$. 近年来, 对额尔古纳地块的 性质及其邻区基础地质研究取得了三个方面的重要 进展，(1) 越来越多的学者认为, 夹持于华北与西伯 利亚两大板块之间的本区及蒙古中部地区是由众多 的具有前寒武纪结晶基底的古老微地块组成的 ${ }^{[8 \sim 12]}$; (2) 对蒙古-鄂霍茨克造山带的研究表明, 蒙古-鄂霍 茨克造山带前身的洋盆, 即杭盖-肯特洋, 不是古亚 洲洋的组成部分, 该造山带西部碰撞发生在晚三叠 早侏罗世, 东部闭合在中侏罗世, 代表北亚克拉通与

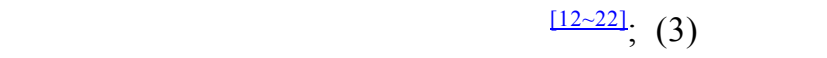
尔古纳地块、莫梅恩地块及佳木斯地块组成岩石的年 代学研究取得了一系列新成果. 在莫梅恩地块“十 月” 杂岩中的黑云母二长花岗岩中获得了 $495 \mathrm{Ma}$ 左 右的 SHRIMP锆石U-Pb年龄 ${ }^{[23]}$; 在额尔古纳地块东 部边缘发现了SHRIMP锆石U-Pb年龄为 $467 \sim 472 \mathrm{Ma}$ 的淡色亚碱性花岗岩 ${ }^{[5,24]}$; 西伯利亚克拉通南缘贝加 尔湖地区西南部Sludyanskiy杂岩中含辉石奥长花岗 岩、二辉奥长花岗岩和含辉石石英正长岩单颗粒锆石 $\mathrm{U}-\mathrm{Pb}$ 年龄为 471 488 $\mathrm{Ma}^{[25]}$; 在佳木斯地块原认为属 太古宙 古元古代的麻山群正、负变质岩中分别获得 了SHRIMP锆石U-Pb年龄为 515 527 Ma的花岗岩体 结晶年龄和 $500 \mathrm{Ma}$ 左右的高级变质作用年龄, 对佳 木斯地块前寒武纪基底提出了质疑, 并指出佳木斯

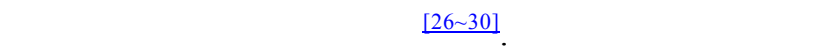
及变质岩高精度的早古生代年龄报道, 表明佳木斯 地块、额尔古纳地块, 直至中蒙古地块北缘与西伯利 亚板块南缘之间可能存在一条规模宏大的早古生代 增生、碰撞造山带, 这一重大基础问题若取得确认, 将直接关系到古亚洲洋盆的划分、西伯利亚板块南缘 的构造演化和泛非运动在中亚-蒙古-兴安巨型复合 
造山带形成过程中的作用. 目前国内尚未见到额尔 古纳地块北部与西伯利亚板块南缘增生、碰撞的可靠 年龄报道. 本次工作选择漠河县西北部的洛古河地 区，通过对花岗岩类野外系统的调研及室内测试工 作, 在前人原划古元古代兴华渡口群中确认出早古 生代的后碰撞花岗岩类, 表明额尔古纳地块北部边 缘与西伯利亚板块南缘在早古生代或更早时期已发 生增生、碰撞作用，并于 504 517 Ma期间完成造山 作用, 古亚洲洋北支 ${ }^{[31,32]}$ 封闭, 结束洋盆演化历史.

《黑龙江省区域地质志》在该区划分出的兴华渡口群 [33], 其时代值得商榷. 本文将通过洛古河岩体岩相 学、岩石地球化学及SHRIMP锆石 U-Pb定年数据探 讨早古生代花岗岩类的形成环境及其大地构造意义.

\section{1 区域地质特征}

传统上认为, 额尔古纳地块的基底由太古宙 古 元古代片麻岩、结晶片岩和古元古代 中元古代角闪 质侵入岩组成; 新元古代砂岩、片岩和碳酸盐岩组成 最初的盖层沉积; 文德 奥陶纪构成晚期盖层, 自下 而上由下部的碎屑岩、中部的碳酸盐岩及上部的砂岩 和片岩组成 ${ }^{[15,33]}$. 但近年来对佳木斯地块基底麻山 群 ${ }^{[26 ~ 30]}$ 和嫩江县新开岭杂岩 ${ }^{[34]}$ 的年代学研究表明, 作为额尔古纳地块基底的兴华渡口群最大形成年龄 似应不超过中元古代晚期, 而不是以前认为的古元 古代, 甚至太古宙. 研究区位于额尔古纳地块北缘, 出露的地层主要为早寒武世额尔古纳河组大理岩、二 云母石英片岩、千枚岩、板岩等和早 中侏罗世陆相 砾岩、砂砾岩、长石石英细砂岩及粉砂岩等. 侵入岩 可划分为两期, 其一为早古生代花岗岩类, 主要岩石 类型为二长花岗岩、石英闪长岩和花岗闪长岩; 其二 为晚中生代细粒花岗岩、花岗斑岩等(图 1). 研究区 西南部及东北部北极村一带有少量泥盆纪泥灰岩、板 岩出露; 在俄国境内的奥利多伊带有志留纪 石炭纪 的陆棚沉积 ${ }^{[35]}$. 额尔古纳地块北缘受到了中 晚侏罗 世形成的蒙古-鄂霍茨克缝合带的强烈改造及上黑龙 江中生代沉积层的覆盖 ${ }^{[15]}$, 致使额尔古纳地块北缘 早古生代花岗岩类呈孤岛状产出. 本文仅研究洛古 河早古生代岩体特征, 探讨其成因及大地构造意义, 晚中生代岩体特征将另文发表.

\section{2 洛古河岩体岩相学特征}

洛古河岩体主要岩石类型为二长花岗岩、石英闪 长岩和花岗闪长岩, 另有少量的闪长岩沙英闪长
岩、石英二长闪长岩、石英二长岩、正长花岗岩及碱 长花岗岩. 根据岩体野外产出状态, 岩石结构、构造 和主要矿物类型及含量, 可将洛古河岩体划分为石 英闪长岩和二长花岗岩 2 个单元.

石英闪长岩单元: 岩体呈近东西向展布于研究 区北部, 出露面积约 $30 \mathrm{~km}^{2}$. 岩体西南部侵入额尔古 纳河组大理岩中, 并在两者接触带形成由透辉石、透 闪石、绿穷石、阳起石等矿物组成的矽卡岩化带; 岩 体东部侵入额尔古纳河组千枚岩、二云母片岩中, 在 两者接触带形成角岩; 岩体南部被中侏罗统二十二 站组覆盖. 岩石呈深灰色, 主要岩石类型为石英闪长 岩、石英二长闪长岩、闪长岩和英云闪长岩. 柱粒结 构、花岗结构, 块状构造, 岩石基本上未变形, 主要 矿物成分为斜长石、角闪石、黑云母及钾长石和石英. 斜长石半自形板状、他形粒状, 可见聚片双晶及卡钠 联合双晶, 晶体一般长 $0.4 \sim 1 \mathrm{~mm}$, 宽 $0.1 \sim 0.5 \mathrm{~mm}$, 最 大晶体长仅 $1.5 \mathrm{~mm}$, 含量 $45 \% \sim 65 \%$; 钾长石他形粒 状, 颗粒较小, 一般无双晶, 偶见卡双晶, 可见交代 包俘斜长石现象, 含量 $2 \% \sim 10 \%$; 石英呈他形粒状, 颗粒较小, 在 $0.3 \sim 0.5 \mathrm{~mm}$ 之间, 有微弱波状消光, 含 量 $2 \% \sim 15 \%$; 角闪石柱状, 晶体较细小, 最长柱约 1.0 $\mathrm{mm}$, 具多色性, 解理清晰, 干涉色二级, 斜消光, 为 普通角闪石，含量 $15 \%$ 30\%; 黑云母鳞片状，多色性 明显, 解理发育, 其与角闪石常伴生, 大小在 $0.3 \sim 0.5$ $\mathrm{mm}$ 之间, 含量 $10 \% \sim 15 \%$. 常见副矿物为榍石和磷 灰石.

二长花岗岩单元: 分布于研究区北部, 两个岩体 均呈近椭圆状产出, 面积约 $40 \mathrm{~km}^{2}$. 岩石呈灰色、灰 白色, 中细不等粒花岗结构, 岩体无明显变形, 基本 不发育类似片麻理的定向构造, 但由于受到中生代 蒙古-鄂霍茨克海剪刀式闭合作用的影响 ${ }^{[18 ~ 20]}$, 岩体 局部地段已糜棱岩化, 片理构造发育, 野外可见长 石、石英均被拉长, 呈长 2.0 5.0 mm的小透镜状, 围 绕其为细碎暗色矿物. 主要岩石类型为二长花岗岩, 另有少量的花岗闪长岩、石英二长岩、正长花岗岩和 碱长花岗岩. 镜下观察, 花岗结构、似斑状结构和碎 裂结构, 块状构造. 主要矿物有斜长石、钾长石、石 英及黑云母和角闪石. 斜长石半自形板状, 为更-中 长石, 大小在 $0.5 \sim 3.5 \mathrm{~mm}$, 聚片双晶发育, 但有的双 晶模糊或渐趋消失, 含量一般 $30 \%$ 50\%, 有个别样品 斜长石含量在 $10 \%$ 左右; 钾长石他形粒状、个别半自 /形板状, 未见双晶, 有的包俘斜长石, 大小在 $0.3 \sim 3.3$ 




图 1 漠河县洛古河地区地质简图

1- - 安山岩; 2- 粉砂岩; 3- 砂岩; 4- 砂岩、砾岩; 5 一泥灰岩、板岩; 6-大理岩; 7一二云母石英片岩、千枚岩及板岩; 8 花岗斑岩; 9- 花岗岩; 10 -二长花岗岩; 11 一石英闪长岩; 12 一断层; 13 - 研究区所在位置; $\mathrm{K}_{1} \mathrm{~s}$ 一一上库力组; $\mathrm{J}_{2} m$ 一一漠河组;



$\mathrm{mm}$, 含量一般在 $20 \% \sim 40 \%$, 个别样品钾长石含量在 $55 \%$ 左右; 石英他形粒状，有裂纹及波状消光，颗粒 较小, 在 $0.3 \sim 0.6 \mathrm{~mm}$ 之间, 含量约 $15 \% \sim 30 \%$; 黑云 母鳞片状, 多碎裂、褪色和析铁, 分布不均匀, 大小 $0.05 \sim 0.4 \mathrm{~mm}$, 含量 5\% 10\%; 有的岩石中见角闪石, 柱状, 最长柱可达 $5 \mathrm{~mm}$, 多色性明显, 含量 $5 \% \sim 8 \%$. 常见副矿物为磷灰石和榍石.

\section{3 洛古河岩体地球化学特征}

\section{1 主量元素特证}

本次工作选取 8 件样品进行了主量元素、稀土元
素及微量元素分析，结果见表 1 . 石英闪长岩单元 $\mathrm{SiO}_{2}$ 含量介于 $54.79 \% \sim 58.30 \%$ 之间，为中性侵入岩; 二长花岗岩单元 $\mathrm{SiO}_{2}$ 含量介于 $65.29 \%$ 66.45\%之间, 为中酸性侵入岩. 前者 $\mathrm{TiO}_{2}, \mathrm{Fe}_{2} \mathrm{O}_{3}, \mathrm{FeO}, \mathrm{MgO}$ 和 $\mathrm{CaO}$ 含量明显高于后者, 但两者的 $\mathrm{Al}_{2} \mathrm{O}_{3}, \mathrm{Na}_{2} \mathrm{O}$ 和 $\mathrm{K}_{2} \mathrm{O}$ 含 量差别不大, $\mathrm{Al}_{2} \mathrm{O}_{3} \geq 15.71 \%, \mathrm{Na}_{2} \mathrm{O}$ 与 $\mathrm{K}_{2} \mathrm{O}$ 的比值平 均为 1.57 , 岩石总体上反映出高 $\mathrm{Al}$ 、高 $\mathrm{Na}$ 特点. 石 英闪长岩单元的 $\mathrm{Na}_{2} \mathrm{O} / \mathrm{CaO}$ 为 $0.79 \sim 1.53$, Shand 指数 介于 $0.77 \sim 0.82$ 之间, 标准矿物中不出现刚玉分子, $\mathrm{Mg}^{\#}$ 指数介于 24 40 之间, 平均为 35 ; 二长花岗岩单 先 $\mathrm{Na}_{2} \mathrm{O} / \mathrm{CaO}$ 为 $1.73 \sim 3.43$, Shand 指数多数 $<1.05$, 为 
表 1 洛古河岩体主量、稀土及微量元素分析结果 ${ }^{\text {a) }}$

\begin{tabular}{|c|c|c|c|c|c|c|c|c|}
\hline 样号 & ML-6 & ML-7 & ML-8 & ML-9 & ML-11 & ML-12 & ML-13 & ML-14 \\
\hline 单元 & \multicolumn{4}{|c|}{ 石英闪长岩单元 } & \multicolumn{4}{|c|}{ 二长花岗岩单元 } \\
\hline $\mathrm{SiO}_{2}$ & 58.13 & 54.79 & 58.30 & 57.57 & 65.29 & 65.48 & 66.45 & 65.53 \\
\hline $\mathrm{TiO}_{2}$ & 1.30 & 1.31 & 1.23 & 1.27 & 0.67 & 0.72 & 0.61 & 0.59 \\
\hline $\mathrm{Al}_{2} \mathrm{O}_{3}$ & 16.44 & 17.06 & 16.00 & 15.84 & 16.68 & 17.04 & 15.71 & 15.85 \\
\hline $\mathrm{Fe}_{2} \mathrm{O}_{3}$ & 1.56 & 2.91 & 1.32 & 1.65 & 0.58 & 0.26 & 0.97 & 1.35 \\
\hline $\mathrm{FeO}$ & 6.43 & 5.96 & 6.60 & 6.60 & 3.09 & 3.32 & 4.18 & 4.94 \\
\hline $\mathrm{MnO}$ & 0.15 & 0.16 & 0.15 & 0.15 & 0.09 & 0.07 & 0.14 & 0.15 \\
\hline $\mathrm{MgO}$ & 2.90 & 1.51 & 2.54 & 2.61 & 1.06 & 1.23 & 0.94 & 0.98 \\
\hline $\mathrm{CaO}$ & 5.62 & 4.45 & 5.09 & 5.22 & 2.33 & 2.72 & 1.62 & 1.70 \\
\hline $\mathrm{Na}_{2} \mathrm{O}$ & 4.43 & 6.82 & 4.38 & 4.26 & 4.98 & 4.71 & 5.56 & 3.47 \\
\hline $\mathrm{K}_{2} \mathrm{O}$ & 2.35 & 2.31 & 3.54 & 3.74 & 4.07 & 3.81 & 2.70 & 4.28 \\
\hline $\mathrm{P}_{2} \mathrm{O}_{5}$ & 0.24 & 0.37 & 0.23 & 0.23 & 0.19 & 0.20 & 0.19 & 0.18 \\
\hline LOI & 0.38 & 2.36 & 0.52 & 0.65 & 0.52 & 0.43 & 0.50 & 0.88 \\
\hline Total & 99.93 & 100.01 & 99.90 & 99.79 & 99.55 & 99.99 & 99.57 & 99.90 \\
\hline $\mathrm{A} / \mathrm{CNK}^{\mathrm{b})}$ & 0.82 & 0.78 & 0.79 & 0.77 & 1.01 & 1.02 & 1.04 & 1.18 \\
\hline $\mathrm{Mg}^{\#}$ & 40 & 24 & 37 & 37 & 34 & 38 & 25 & 22 \\
\hline $\mathrm{La}$ & 30 & 33 & 33 & 35 & 41 & 60 & 51 & 62 \\
\hline $\mathrm{Ce}$ & 67 & 75 & 77 & 83 & 98 & 134 & 99 & 129 \\
\hline $\operatorname{Pr}$ & 8.55 & 10.56 & 10.58 & 10.99 & 13.67 & 17.71 & 14.32 & 18.76 \\
\hline $\mathrm{Nd}$ & 35.59 & 41.69 & 43.90 & 44.28 & 55.61 & 71.28 & 53.98 & 71.11 \\
\hline $\mathrm{Sm}$ & 7.82 & 8.78 & 9.18 & 9.09 & 11.67 & 14.66 & 10.10 & 11.84 \\
\hline $\mathrm{Eu}$ & 1.97 & 2.12 & 1.89 & 1.83 & 1.38 & 1.52 & 1.37 & 1.61 \\
\hline $\mathrm{Gd}$ & 7.37 & 7.72 & 8.57 & 8.62 & 9.97 & 12.93 & 8.24 & 9.61 \\
\hline $\mathrm{Tb}$ & 1.29 & 1.29 & 1.48 & 1.46 & 1.65 & 2.14 & 1.35 & 1.41 \\
\hline Dy & 8.13 & 7.87 & 9.13 & 9.00 & 9.96 & 13.03 & 7.86 & 8.11 \\
\hline Ho & 1.59 & 1.52 & 1.80 & 1.79 & 1.86 & 2.36 & 1.45 & 1.45 \\
\hline $\mathrm{Er}$ & 4.73 & 4.54 & 5.45 & 5.29 & 5.21 & 7.02 & 4.26 & 4.20 \\
\hline $\mathrm{Tm}$ & 0.72 & 0.70 & 0.82 & 0.77 & 0.75 & 0.97 & 0.62 & 0.59 \\
\hline $\mathrm{Yb}$ & 4.7 & 4.7 & 5.4 & 5.1 & 4.6 & 5.9 & 4.2 & 4.0 \\
\hline $\mathrm{Lu}$ & 0.72 & 0.70 & 0.82 & 0.77 & 0.64 & 0.80 & 0.59 & 0.56 \\
\hline$\Sigma \mathrm{REE}$ & 180.18 & 200.19 & 209.02 & 216.99 & 255.97 & 344.32 & 258.34 & 324.25 \\
\hline $\mathrm{Eu} / \mathrm{Eu}^{*}$ & 0.78 & 0.77 & 0.64 & 0.62 & 0.38 & 0.33 & 0.45 & 0.45 \\
\hline$(\mathrm{La} / \mathrm{Yb})_{\mathrm{N}}$ & 4.30 & 4.73 & 4.12 & 4.63 & 6.01 & 6.86 & 8.19 & 10.45 \\
\hline $\mathrm{Sr}$ & 329 & 349 & 296 & 282 & 272 & 291 & 199 & 189 \\
\hline $\mathrm{Rb}$ & 135 & 212 & 193 & 195 & 349 & 376 & 358 & 515 \\
\hline $\mathrm{Ba}$ & 491 & 380 & 735 & 789 & 696 & 655 & 400 & 668 \\
\hline Th & 18.2 & 26.1 & 21.2 & 20.7 & 27.2 & 27.7 & 22.5 & 26.0 \\
\hline $\mathrm{Nb}$ & 17.9 & 26.4 & 20.0 & 19.7 & 30.2 & 27.1 & 15.8 & 19.6 \\
\hline $\mathrm{Zr}$ & 398 & 307 & 438 & 412 & 422 & 479 & 390 & 365 \\
\hline Cs & 10.5 & 51.4 & 15.1 & 19.3 & 36.4 & 44.4 & 33.6 & 64.9 \\
\hline $\mathrm{Ga}$ & 21.7 & 26.9 & 24.1 & 24.1 & 27.6 & 24.6 & 17.0 & 22.9 \\
\hline $\mathrm{Hf}$ & 13.8 & 11.8 & 17.6 & 16.9 & 12.0 & 13.8 & 10.8 & 10.8 \\
\hline $\mathrm{Sc}$ & 23.1 & 14.6 & 23.1 & 25.3 & 17.9 & 16.7 & 10.2 & 12.2 \\
\hline $\mathrm{Cr}$ & 19.8 & 10.0 & 14.7 & 12.2 & 12.0 & 11.3 & 9.1 & 7.7 \\
\hline V & 104.7 & 58.1 & 96.9 & 100.4 & 41.6 & 42.0 & 36.7 & 29.6 \\
\hline $\mathrm{Ni}$ & 8.4 & 5.7 & 6.8 & 7.8 & 15.7 & 14.3 & 9.0 & 15.8 \\
\hline $\mathrm{U}$ & 3.2 & 4.5 & 3.9 & 4.0 & 5.7 & 4.7 & 5.5 & 9.9 \\
\hline $\mathrm{Y}$ & 26.3 & 35.0 & 39.5 & 45.7 & 37.9 & 54.3 & 30.7 & 26.5 \\
\hline $\mathrm{Ta}$ & 1.85 & 2.61 & 1.98 & 1.86 & 2.44 & 2.24 & 1.37 & 1.66 \\
\hline
\end{tabular}

a) 样品由国土资源部廊坊物化探研究所实验室测定; 主量元素采用 XRF 分析; 稀土和微量元素采用 ICP-MS 分析. 主量元素单位 $w_{\mathrm{B}} / \%$, 稀土和微量元素单位为 $\mu \mathrm{g} / \mathrm{g}$. b) $\mathrm{A} / \mathrm{CNK}=\mathrm{Al}_{2} \mathrm{O}_{3} /\left(\mathrm{CaO}+\mathrm{Na}_{2} \mathrm{O}+\mathrm{K}_{2} \mathrm{O}\right)$ 分子数, $\mathrm{Mg}^{\#}=100 \times\left[\mathrm{Mg}^{2+} /\left(\mathrm{Mg}^{2+}+\mathrm{Fe}^{2+}\right)\right]$ 原子数 


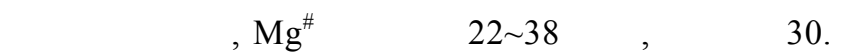
与巴尔巴林(Barbarin)花岗岩类分类标准 ${ }^{[36,37]}$ 对比, 石英闪长岩单元相当于含角闪石钙碱性花岗岩类 (ACG), 而二长花岗岩单元相当于高钾钙碱性花岗岩 类(KCG). 主量元素特征表明, 洛古河岩体主要形成 于构造转换时期, 从石英闪长岩单元到二长花岗岩 单元岩浆演化程度不断提高, 壳源物质逐渐增多, 而 幔源物质逐渐减少.

在实际矿物含量 QAP 分类图解中(图 2(a)), 石英 闪长岩单元为中性岩组合, 岩石类型为石英闪长岩、 石英二长闪长岩、闪长岩和英云闪长岩; 二长花岗岩 单元为中酸性岩组合, 岩石类型主要为二长花岗岩,


图 2

(a) 花岗岩类实际矿物含量QAP分类图解(底图据文献[38]); (b) $\mathrm{SiO}_{2}$ 与 $\mathrm{K}_{2} \mathrm{O}$ 关系图解(分类据文献[39]). 1-石英闪长岩单元; 2 -二长 花岗岩单元 https://engine.scichina.cc
其次为花岗闪长岩、石英二长岩、正长花岗岩及碱长 花岗岩. 在 $\mathrm{SiO}_{2}-\mathrm{K}_{2} \mathrm{O}$ 图解中(图 2(b)), 石英闪长岩单 元与二长花岗岩单元基本上都为高钾钻碱性系列, 个别为橄榄安粗岩系列.

\section{2 稀土元素特征}

由表 1 可知, 石英闪长岩单元稀土元素总量为 $180.18 \sim 216.99 \mu \mathrm{g} / \mathrm{g}$, 具有弱的 $\mathrm{Eu}$ 负异常 $(0.70 \sim 0.82)$, 稀土元素分馏不明显 $\left((\mathrm{La} / \mathrm{Yb})_{\mathrm{N}}\right.$ 介于 4.12 4.73); 二长 花岗岩单元稀土元素总量为 $255.97 \sim 344.32 \mu \mathrm{g} / \mathrm{g}$, 具 明显的 $\mathrm{Eu}$ 负异常 $(0.33 \sim 0.45)$, 稀土元素分馏中等 $\left((\mathrm{La} / \mathrm{Yb})_{\mathrm{N}}\right.$ 介于 $\left.6.01 \sim 10.45\right)$, 稀土配分曲线为轻稀土 富集型(图 3(a)). 从石英闪长岩单元到二长花岗岩单 元, 稀土总量增加, $\mathrm{Eu}$ 负异常越来越明显, 轻重稀土 分馏程度增大, 表明岩浆分异程度越来越高. 但总体
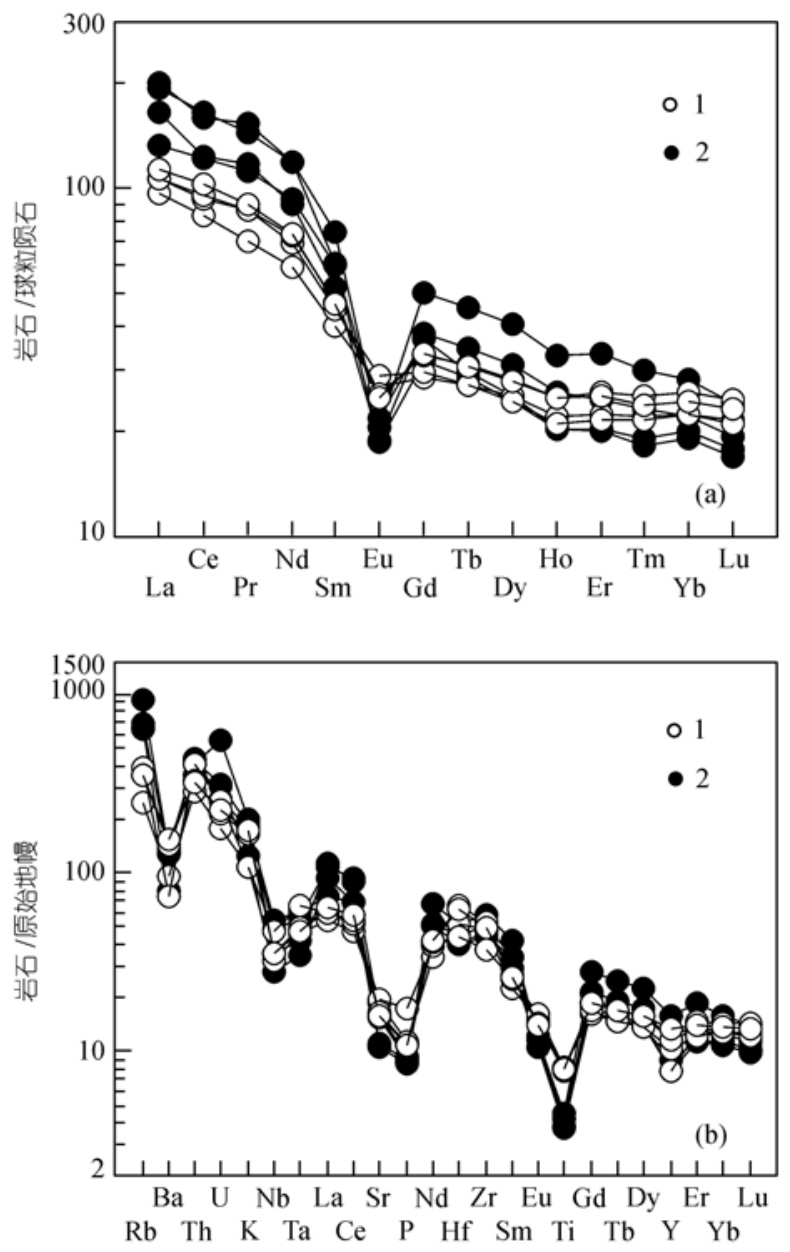

图 3 洛古河岩体稀土元素配分曲线(a)和微量元素原始地 幔标准化蛛网图(b)

标准化数值分别取自文献 $[40,45]$. 图例同图 2, 下同 
上看, 洛古河岩体具有弱 中等程度的轻重稀土分馏. 研究表明, 典型岛弧、山弧环境下的钙碱性安山岩和 英安岩HREE较富集 $(\mathrm{Yb} \geq 2.50 \mu \mathrm{g} / \mathrm{g}), \mathrm{REE}$ 分异程度 较低 $\left((\mathrm{La} / \mathrm{Yb})_{\mathrm{N}}<10\right)$, 具有 $\mathrm{Eu}$ 的负异常 ${ }^{[41]}$. 洛古河岩 体稀土元素配分曲线特征与典型岛弧、山弧环境下的 钙碱性中酸性火成岩相似, 但其稀土总量明显高于 岛弧、山弧环境下的钙碱性中酸性火成岩. 说明该岩 体成因的复杂性.

\section{3 微量元素特征}

从微量元素丰度(表 1)来看, 洛古河岩体的大离 子亲石元素如 $\mathrm{Sr}$ 和 $\mathrm{Ba}$ 等含量较低(分别为 276,602 $\mu \mathrm{g} / \mathrm{g}$ ), 与安第斯活动大陆边缘火成岩微量元素特征 明显不同. 与岛弧火成岩对比 ${ }^{[42]}$, 两者在 $\mathrm{Sr}, \mathrm{Ba}, \mathrm{Nb}$, $\mathrm{Y}, \mathrm{Ni}, \mathrm{Cr}, \mathrm{V}$ 和 Sc等元素含量上相近, 而放射性元素如 $\mathrm{Th}$ 和U及稀有元素 $\mathrm{Rb}$ 和 $\mathrm{Cs}$ 等含量高于岛弧火成岩. 洛 古河岩体微量元素特征与泛非(Pan-Afrian)运动后的 Tuareg地盾后碰撞花岗岩类微量元素特征 ${ }^{[43,44]}$ 相似. 在微量元素蛛网图(图 3(b))上, 富集 Rb, Th, U, K, La, $\mathrm{Ce}, \mathrm{Nd}, \mathrm{Hf}, \mathrm{Zr}$ 和 $\mathrm{Sm}$ 等元素, 而强烈亏损 $\mathrm{Ba}, \mathrm{Nb}, \mathrm{Ta}, \mathrm{Sr}$, $\mathrm{P}$ 和 Ti等元素, 与海西期科西嘉造山花岗岩基的微量 元素蛛网图相比, 两者在许多方面相近 ${ }^{[46]}$. 上述微量 元素特征表明洛古河岩体为与陆-陆碰撞有关的后碰 撞造山花岗岩类, 形成于额尔古纳地块与西伯利亚 板块主碰撞之后的陆内超碰撞阶段.

\section{4 洛古河岩体 SHRIMP 锆石 U-Pb 年龄}

\section{1 样品制备及分析方法}

锆石由沈阳地质矿产研究所地质实验组按常规 重力和磁选方法分选, 为保证各粒级锆石颗粒的完 整性, 将重约十公斤的岩石经过粗碎及中碎, 将粉碎 后的样品分粒级进行淘洗. 在双目显微镜下对所选 锆石观察发现, 石英闪长岩单元中的锆石为无色-淡 黄色, 透明, 四方柱状, 多数雉体发育不完整, 晶体 完整者少见, 大部分颗粒较纯净, 少数含有暗色包体, 金刚光泽, 长宽比 $4: 1 \sim 2: 1$, 晶体大者 $0.25 \mathrm{~mm} \times 0.1$ $\mathrm{mm}$, 一般 $0.05 \mathrm{~mm} \times 0.02 \mathrm{~mm} \sim 0.1 \mathrm{~mm} \times 0.03 \mathrm{~mm}$; 二 长花岗岩单元中的锆石为褐黄色-淡黄色, 透明-半透 明, 四方柱体发育, 晶体完整者较少, 锆石颗粒纯净, 无包体, 玻璃光泽, 长宽比 3:1 2: 1, 个别锆石长宽比 可达 5: 1, 晶体大者 $0.25 \mathrm{~mm} \times 0.1 \mathrm{~mm}$, 一般 $0.15 \mathrm{~mm}$ $\times 0.06 \mathrm{~mm} \sim 0.06 \mathrm{~mm} \times 0.03 \mathrm{~mm}$. 最后, 将锆石与数 粒RSES参考样TEM置于环氧树脂中, 磨制约一半大小,
使锆石内部暴露, 用于阴极发光和SHRIMP U-Pb分 析. 锆石阴极发光研究在中国科学院地质与地球物 理研究所电子探针研究室完成, SHRIMP U-Pb分析在 中国地质科学院地质研究所SHRIMP II 上完成, 样品 分析流程及原理参见文献[47,48]. 应用RSES参考锆 石 TEM(417 Ma) 进行元素间的分馏校正，应用 $\mathrm{SL} 13$ (年龄为 $572 \mathrm{Ma}, \mathrm{U}$ 含量 $238 \mu \mathrm{g} / \mathrm{g}$ ) 标定样品的U, $\mathrm{Th}$ 和 $\mathrm{Pb}$ 含量. 数据处理采用Ludwing SQUID1.0 及 ISOPLT程序. 应用实测 ${ }^{204} \mathrm{~Pb}$ 校正锆石中的普通铅. 采用年龄为 ${ }^{206} \mathrm{~Pb} /{ }^{238} \mathrm{U}$ 年龄.

\section{2 分析结果}

样品中锆石阴极发光图像显示, 石英闪长岩单 元的 ML-7 样品中大多数锆石晶体形态较好, 呈单雉 或双雉状, 具清楚的生长韵律环带, 个别锆石晶体呈 不规则四边形(图 4(a)); 二长花岗岩单元的 ML-14 样 品锆石晶形均为单锥或双雉状, 生长韵律环带清楚, 锆石晶形较 ML-7 样品好(图 4(b)). 反映了洛古河岩 体岩浆锆石结构特征.

锆石SHRIMP分析结果见表 2. 可以看出, 石英 闪长岩单元的 $U$ 和 Th含量相对较低, 分别介于 $414 \sim 787 \mu \mathrm{g} / \mathrm{g}$ 和 116 436 $\mu \mathrm{g} / \mathrm{g}$ 之间, 而二长花岗岩单 元的U和 Th含量相对较高, 分别介于 415 2484 和 132 633 $\mu \mathrm{g} / \mathrm{g}$ 之间. 经计算, 洛古河岩体的 $\mathrm{Th} / \mathrm{U}$ 比值 变化较小, 且都大于 0.1 (介于 $0.25 \sim 0.77$ 之间). 研究 表明, 岩浆型锆石的 $T h / U$ 比值大于 0.1 , 而且各锆石 的Th, U之间具有正相关关系 ${ }^{[49]}$. 据此说明洛古河岩 体中的锆石为岩浆型锆石.

锆石 SHRIMP U-Pb 测年结果显示, 石英闪长岩 单元 ML-7 样品中锆石 10 个点的 ${ }^{206} \mathrm{~Pb} /{ }^{238} \mathrm{U}$ 年龄为 503 527 Ma, 变化范围较小, 在一致曲线图中, 数据 点集中分布(图 5(a)), 其 ${ }^{206} \mathrm{~Pb} /{ }^{238} \mathrm{U}$ 年龄的加权平均值 为 $517 \pm 9 \mathrm{Ma}$, 代表洛古河石英闪长岩单元岩体的结 晶年龄. 二长花岗岩单元 ML-14 样品中锆石 12 个点 的 ${ }^{206} \mathrm{~Pb} /{ }^{238} \mathrm{U}$ 年龄为 $492 \sim 518 \mathrm{Ma}$, 变化范围亦较小, 在一致曲线图中, 除 1 个点外, 其他数据点集中分布 (图 5(b)), 其 ${ }^{206} \mathrm{~Pb} /{ }^{238} \mathrm{U}$ 年龄的加权平均值为 $504 \pm 8$ $\mathrm{Ma}$ ，代表了洛古河二长花岗岩单元岩体的结晶年龄.

\section{5 讨论}

近年来, 通过对大陆碰撞带与花岗岩带形成演 化过程的深入研究 ${ }^{[36,37,50 \sim 52]}$ 认为, 大陆之间的碰撞作 用发生以后，虽然导致海洋消失进入陆内环境，但大 陆之间还经历了一段相当长的仍然与碰撞作用有关 

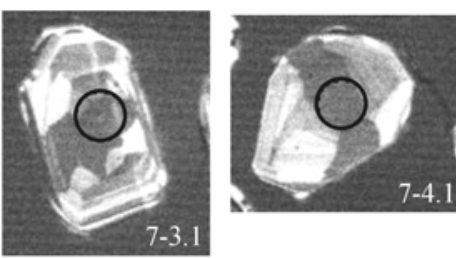

$100 \mu \mathrm{m}$

(b)
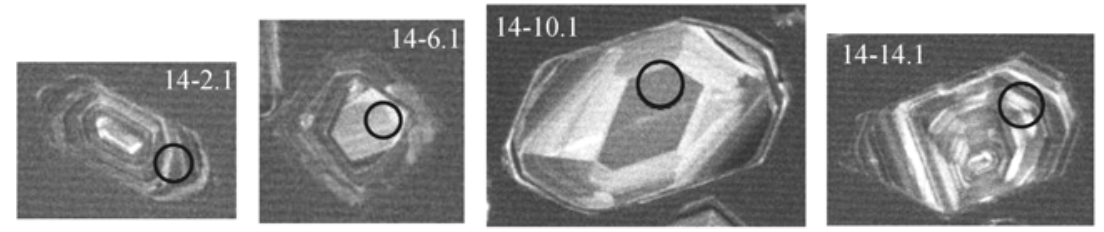



(a)



图 4 洛古河岩体石英闪长岩(a)和二长花岗岩(b)中部分锆石的形态及分析点位图

表 2 洛古河岩体锆石 SHRIMP U-Pb 分析结果 ${ }^{a}$

\begin{tabular}{|c|c|c|c|c|c|c|c|c|c|}
\hline 测试点 & ${ }^{206} \mathrm{Pbc} / \%$ & $\mathrm{U} / \mu \mathrm{g} \cdot \mathrm{g}^{-1}$ & $\mathrm{Th} / \mu \mathrm{g} \cdot \mathrm{g}^{-1}$ & ${ }^{232} \mathrm{Th} /{ }^{238} \mathrm{U}$ & ${ }^{206} \mathrm{~Pb} / \mu \mathrm{g} \cdot \mathrm{g}^{-1}$ & $\begin{array}{c}{ }^{206} \mathrm{~Pb} /{ }^{238} \mathrm{U} \\
\text { 年龄/ } \mathrm{Ma}\end{array}$ & $\begin{array}{c}{ }^{207} \mathrm{~Pb}^{* /} \\
{ }^{206} \mathrm{~Pb}^{*}(\%)\end{array}$ & $\begin{array}{l}{ }^{207} \mathrm{~Pb}^{* /} / \\
{ }^{235} \mathrm{U}(\%)\end{array}$ & $\begin{array}{l}{ }^{206} \mathrm{~Pb}^{* /} \\
{ }^{238} \mathrm{U}(\%)\end{array}$ \\
\hline ML7-1.1 & 0.73 & 690 & 323 & 0.48 & 49.8 & $516 \pm 14$ & $0.0572(3.2)$ & $0.657(4.2)$ & $0.0834(2.8)$ \\
\hline ML7-2.1 & 0.26 & 414 & 116 & 0.29 & 29.5 & $513 \pm 14$ & $0.0584(2.0)$ & $0.667(3.4)$ & $0.0828(2.8)$ \\
\hline ML7-3.1 & 0.51 & 484 & 178 & 0.38 & 33.9 & $503 \pm 13$ & $0.0570(2.6)$ & $0.638(3.8)$ & $0.0812(2.8)$ \\
\hline ML7-4.1 & 0.54 & 571 & 246 & 0.45 & 41.4 & $519 \pm 14$ & $0.0546(2.8)$ & $0.631(3.9)$ & $0.0838(2.8)$ \\
\hline ML7-5.1 & 0.57 & 429 & 193 & 0.46 & 31.6 & $527 \pm 14$ & $0.0573(2.9)$ & $0.673(4.1)$ & $0.0851(2.8)$ \\
\hline ML7-6.1 & 0.42 & 787 & 436 & 0.57 & 56.9 & $518 \pm 14$ & $0.0573(2.1)$ & $0.662(3.5)$ & $0.0837(2.7)$ \\
\hline ML7-7.1 & 0.36 & 479 & 129 & 0.28 & 34.6 & $520 \pm 14$ & $0.0568(2.9)$ & $0.658(4.0)$ & $0.0839(2.8)$ \\
\hline ML7-8.1 & 0.29 & 742 & 256 & 0.36 & 54.0 & $522 \pm 14$ & $0.0570(2.0)$ & $0.663(3.4)$ & $0.0844(2.7)$ \\
\hline ML7-9.1 & 0.23 & 662 & 312 & 0.49 & 47.3 & $514 \pm 13$ & $0.0587(1.9)$ & $0.672(3.3)$ & $0.0830(2.7)$ \\
\hline ML7-10.1 & 0.79 & 724 & 352 & 0.50 & 52.9 & $523 \pm 14$ & $0.0541(2.9)$ & $0.629(4.0)$ & $0.0844(2.7)$ \\
\hline ML14-2.1 & 0.26 & 1070 & 443 & 0.43 & 77.0 & $518 \pm 14$ & $0.0573(1.8)$ & $0.661(3.3)$ & $0.0836(2.7)$ \\
\hline ML14-3.1 & 0.17 & 1440 & 530 & 0.38 & 101 & $504 \pm 13$ & $0.0582(1.4)$ & $0.652(3.1)$ & $0.0813(2.7)$ \\
\hline ML14-4.1 & 1.23 & 733 & 267 & 0.38 & 50.3 & $492 \pm 13$ & $0.0518(4.3)$ & $0.563(5.1)$ & $0.0788(2.8)$ \\
\hline ML14-5.1 & 0.38 & 657 & 212 & 0.33 & 46.6 & $510 \pm 14$ & $0.0563(2.4)$ & $0.638(3.7)$ & $0.0822(2.7)$ \\
\hline ML14-6.1 & 0.24 & 731 & 246 & 0.35 & 51.0 & $501 \pm 14$ & $0.0579(2.0)$ & $0.646(3.4)$ & $0.0809(2.8)$ \\
\hline ML14-7.1 & 0.19 & 1241 & 378 & 0.31 & 88.7 & $514 \pm 14$ & $0.0574(1.4)$ & $0.657(3.1)$ & $0.0831(2.7)$ \\
\hline ML14-8.1 & 0.72 & 589 & 453 & 0.80 & 42.6 & $518 \pm 14$ & $0.0570(3.1)$ & $0.657(4.2)$ & $0.0835(2.7)$ \\
\hline ML14-10.1 & 0.71 & 415 & 132 & 0.33 & 29.4 & $510 \pm 14$ & $0.0539(2.2)$ & $0.610(3.6)$ & $0.0820(2.8)$ \\
\hline ML14-11.1 & 0.12 & 2484 & 633 & 0.26 & 170 & $495 \pm 13$ & $0.0575(0.89)$ & $0.633(2.8)$ & $0.0798(2.7)$ \\
\hline ML14-13.1 & 0.27 & 873 & 260 & 0.31 & 60.4 & $500 \pm 13$ & $0.0544(1.7)$ & $0.603(3.2)$ & $0.0804(2.7)$ \\
\hline ML14-14.1 & 0.35 & 579 & 365 & 0.65 & 40.5 & $503 \pm 14$ & $0.0566(2.4)$ & $0.633(3.6)$ & $0.0811(2.7)$ \\
\hline ML14-15.1 & 0.72 & 448 & 192 & 0.44 & 30.7 & $492 \pm 13$ & $0.0560(3.4)$ & $0.612(4.4)$ & $0.0791(2.8)$ \\
\hline
\end{tabular}

a) 误差为 $1 \sigma ; \mathrm{Pbc}$ 和 $\mathrm{Pb}$ *分别为普通和放射成因 $\mathrm{Pb}$. 标准的误差是 $0.75 \%$, 普通 $\mathrm{Pb}$ 用测量的 ${ }^{204} \mathrm{~Pb}$ 校正 

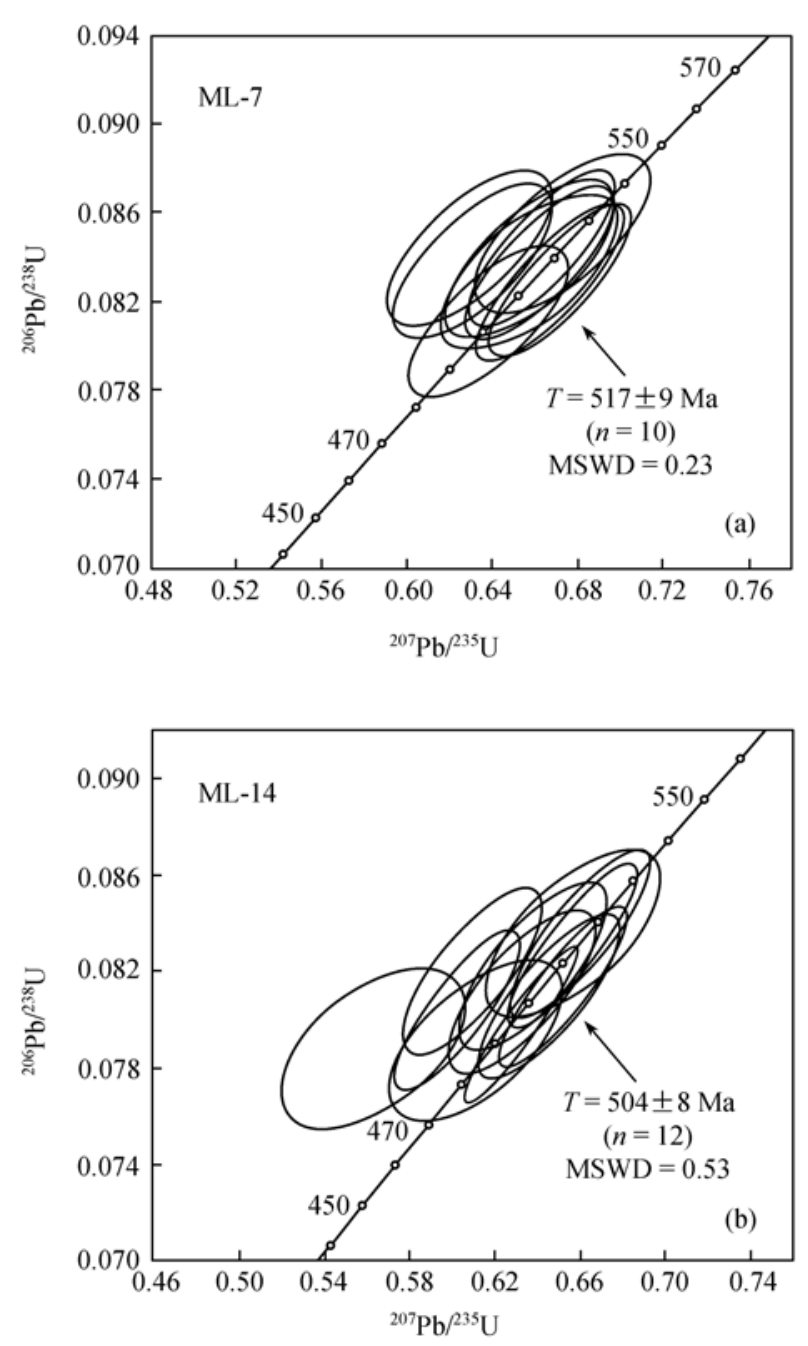

图 5 洛古河岩体锆石的 SHRIMP U-Pb 年龄谐和图

(a) 石英闪长岩单元(ML-7); (b) 二长花岗岩单元(ML-14)

的会聚作用; 同时还发现大陆主碰撞期不利于岩浆 上升，大量的岩浆作用发生在主碰撞期之后，板内时 期之前. Liegeois把主海洋关闭以后的, 连续的板块汇 聚导致产生陆内的逆冲、扭动构造和地块的横向挤压 或逃逸, 或沿巨大剪切带仍然有大量水平方向块体 运动的陆内环境称为 后碰撞作用” (post-collision) $)^{[53]}$. 洛古河岩体以二长质岩石为主, 主要岩石类型为二 长花岗岩、石英闪长岩和花岗闪长岩, 另有少量的闪 长岩、英云闪长岩、石英二长闪长岩、石英二长岩、 正长花岗岩及碱长花岗岩, 属高钾钙碱性岩系, 与后 碰撞阶段形成的高钾钲碱性花岗岩 $(K C G)$ 岩石组合 ${ }^{[53 \sim 55]}$ 相一致. 微量元素汤氏蛛网图上富集LILE, 贫 化HFSE, 强烈亏损Nb, Ta, P和Ti等元素,, 显示后碰撞
高钾钙碱性I型花岗岩微量元素特征 $[56,57]$. 在花岗岩 类形成环境的 $R_{1}-R_{2}$ 判别图解(图 6(a))中, 洛古河岩体 石英闪长岩单元投影点基本上都落入板块碰撞后隆 起期花岗岩区( III 区), 二长花岗岩单元投影点全部落 入造山晚期花岗岩区(IV区); 在 Rb-Yb+Ta(图 6(b))和 $\mathrm{Rb}-\mathrm{Y}+\mathrm{Nb}$ 判别图(图 6(c))中, 石英闪长岩单元落入火 山弧花岗岩与同碰撞花岗岩的过渡带, 而二长花岗 岩单元落入同碰撞花岗岩区; 在Nb-Y判别图(图 6(d)) 中, 样品落入火山弧花岗岩、同碰撞花岗岩与板内花 岗岩的过渡带. 综上所述, 洛古河岩体形成于主碰撞 之后的隆升期及造山晚期. 其主量、微量元素特征与 泛非运动后的Tuareg地盾花岗岩类特征相似 ${ }^{[43,44]}$, 为 后碰撞花岗岩类. 洛古河岩体可能形成于额尔古纳 地块与西伯利亚板块增生-碰撞-造山阶段的晚期, 标 志着萨拉伊尔运动结束于 $500 \mathrm{Ma}$ 左右.

如前所述, 近年来在额尔古纳地块及其毗邻地 区获得了一批高精度的 SHRIMP 锆石 U-Pb 年龄 $[5,23,24,27 \sim 30]$ 及单颗粒锆石 U-Pb年龄 ${ }^{[25,26]}$. 本文又在额 尔古纳地块北缘漠河地区厘定出早古生代后碰撞花 岗岩类, SHRIMP锆石U-Pb年龄为 504 517 Ma. 区域 上已知奥陶纪安娘娘桥组不整合于上述增生杂岩之 上 ${ }^{[1]}$. 上述事实说明在中蒙古地块、额尔古纳地块和 佳木斯地块北缘与西伯利亚板块南缘之间存在一条 规模宏大的早古生代增生、碰撞造山带, 为萨拉伊尔 运动的结果. 在华北地台北缘内蒙古中部温都尔庙 图林凯地区的石英闪长岩SHRIMP锆石U-Pb年龄为 $467 \pm 13 \mathrm{Ma}$, 被认为是温都尔庙洋壳在早古生代的 一次消减事件 ${ }^{[60]}$; 锡林浩特杂岩中的具岛弧性质的 石英闪长岩、花岗闪长岩、斜长花岗岩锆石 $\mathrm{U}-\mathrm{Pb}$ 年龄 分别为 499,447 和 $452 \mathrm{Ma}$, 表明早奥陶世(或稍早)开始 出现温都尔庙古海沟与华北古板块之间的火山岛弧堆 积 ${ }^{[61]}$; 白乃庙的花岗岩锆石U-Pb年龄为 $454 \mathrm{Ma}$, 表明 华北北缘在奥陶纪时的洋壳俯冲和岛弧活动 ${ }^{[62]}$; 在 嫩江断裂以西发育有奥陶纪 泥盆纪岛弧-弧后盆地 火山沉积建造 ${ }^{[63]}$; 多宝山、铜山地区的辉钼矿 Re-Os 法同位素测年，获得等时线年龄 $506 \pm 14 \mathrm{Ma}$, 被认 为是下奥陶统岛弧安山岩的成岩年龄 ${ }^{[64]}$.

上述资料表明，早古生代时期额尔古纳地块南 北两侧具有不同的构造演化历史. 沿佳木斯地块、额 尔古纳地块直至中蒙古地块北缘 $500 \mathrm{Ma}$ 的后碰撞花 岗岩类的发现, 表明西伯利亚板块南缘增生-碰撞-造 山作用在 $500 \mathrm{Ma}$ 左右已基本结束, 转入后碰撞阶段; 

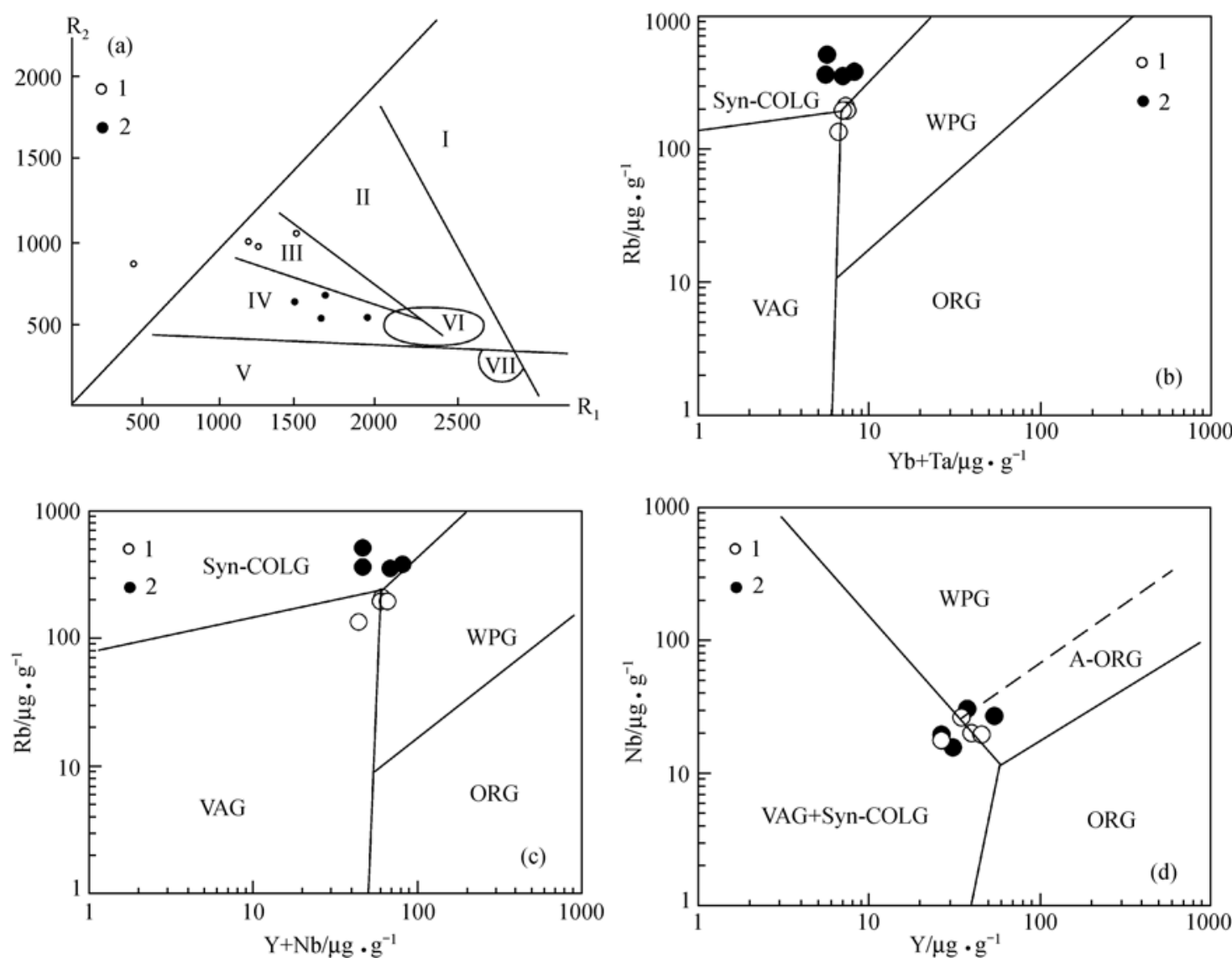

图 6 洛古河岩体形成的构造环境判别图

(a) $\mathrm{R}_{1}-\mathrm{R}_{2}$ 判别图(底图据文献[58]); (b) Rb-Yb+Ta判别图(底图据文献[59]); (c) Rb-Y+Nb判别图(底图据文献[59]); (d) Nb-Y判别图 (底图据文献[59])

467 472 Ma 之间的 A 型淡色亚碱性花岗岩的出现, 标志着该区已转入板内环境. 然而, 华北地台北缘在 460 480 Ma 之间主要表现为洋壳的俯冲、消减, 形 成大量的岛弧型火山岩和花岗岩类, 具有造山早期 活动大陆边缘特征. 说明古亚洲洋南北两侧构造演 化在时间上存在不对称性, 早古生代早期的萨拉伊 尔运动使北部洋盆最终封闭, 而南部洋盆直到晚古 生代才最终闭合, 完成洋盆演化历史, 当时的构造格 局具有此张彼合的特点.

\section{6 结论}

(i ) 洛古河岩体为高钾钙碱性岩系, 主要岩石类 型为二长花岗岩、石英闪长岩和花岗闪长岩, 另有少量 的闪长岩、英云闪长岩、石英二长闪长岩、石英二长岩、 正长花岗岩及碱长花岗岩, 属后碰撞花岗岩类.

(ii) 岩体 SHRIMP 锆石 U-Pb 年龄为 $504 \pm$

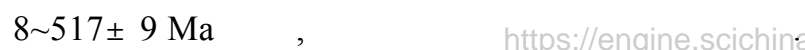

（iii）萨拉伊尔运动使额尔古纳地块增生于西伯 利亚板块南缘, 古亚洲洋北支封闭, 完成了古亚洲洋 北洋的演化历史.

致谢 参加项目野外工作的还有韩仲文研究员, 赵俊才、王 启志高级工程师, 王宏博、杨易堂工程师. 成文过程中与 张允平研究员进行了多次讨论, 对笔者很有启发. 张允平、 唐克东研究员审阅了初稿, 并提出了宝贵建议. 在论文修 改过程中得到了中国科学院地质与地球物理研究所吴福元 教授, 中国地质科学院地质研究所李锦轶研究员的大力帮 助, 并提供了最新的参考文献. 在此一并致以诚挚的感谢. 本项工作得到了国土资源部地质勘查司国家资源补偿费项 目(GZB2001-01)资助.

\section{参考文献}

1 Li C Y, Wang Q, Liu X Y, et al. Explanatory Notes to the Tectonic Map of Asia. Beijing: Cartographic Publishing House, 1982. 1 49

2 王荃, 刘雪亚, 李锦轶. 中国华夏与安加拉古陆间的板块构造. 北京: 北京大学出版社, 1991. 1 151 
3 李锦轶. 中国东北及邻区若干地质构造问题的新认识. 地质论 评, 1998, 44(4): 339 347

4 Ren J S, Wang Z X, Chen B W, et al. The Tectonics of China from A Global View_ A Guide to the Tectonic Map of China and Adjacent Region. Beijing: Geological Publishing House, 1999. 1 32

5 Sorokin A A, Kudryashov N M, Li J Y, et al. Early Paleozoic granitoids in the eastern margin of the Argun' terrane, Amur area: first geochemical and geochronologic data. Petrology, 2004, 12(4): $367 \sim 376$

6 黄汲清, 任纪舜, 姜春发, 等. 中国大地构造基本轮廓. 地质学 报, 1977, 51(2): 117 135

7 任纪舜, 陈廷愚, 刘志刚. 中国东部构造单元划分的几个问题. 地质论评, 1984, 30(4): 382 385

8 邵济安, 唐克东. 中国东北地体与东北亚大陆边缘演化. 北京: 地震出版社, 1995, 11 39

9 邵济安, 唐克东, 王成源. 那丹哈达地体的构造特征及其演化 中国科学, B 辑, 1991, (7): 744 751

10 李双林，欧阳自远. 兴蒙造山带及邻区的构造格局与构造演化. 海洋地质与第四纪地质, 1998, 18(3): 45 54

11 王道永, 王成善, 杜思清. 内蒙古东北部及周边地区前中生代 构造发展演化史. 成都理工学院学报, 1998, 25(4): 529 536

12 Parfenov L M, Popeko L I, Tomurtogoo O. Problems of the tectonics of the Mongolia-Okhotsk orogenic belt. Tikhookean. Geol, 1999, 18(5): 24 43

13 Zorin Yu A, Belichenko V G, Turutanov E Kh, et al. The South Siberia-central Mongolia transect. Tectonophysics, 1993, 225: $361 \sim 378$ [DOI]

14 Zorin Yu A, Belichenko V G, Turutanov E Kh, et al. The Baikal-Mongolia transect. Russian Geology and Geophysics, 1994, 7-8: $94 \sim 110$

15 Zorin Yu A, Belichenko V G, Turutanov E Kh, et al. The East Siberia transect. International Geology Review, 1995, 37: 154 175

16 Zorin $\mathrm{Yu}$ A. Geodynamics of the western part of the Mongolia-Okhotsk collisional belt, Trans-Baikal region (Russia) and Mongolia. Tectonophysics, 1999, 306: 33 56[DOI]

17 Sorokin A A, Yarmolyuk V V, Kotov A B, et al. Geochronology of Triassic-Jurassic granitoids in the southern framing of the Mongolia-Okhotsk foldbelt and the problem of early Mesozoic granite formation in central and eastern Asia. Doklady Earth Sciences, 2004, 399: 1091 1094

$18 \mathrm{Li} \mathrm{J} \mathrm{Y,} \mathrm{He} \mathrm{Z} \mathrm{J,} \mathrm{Mo} \mathrm{S} \mathrm{G,} \mathrm{et} \mathrm{al.} \mathrm{The} \mathrm{late} \mathrm{Mesozoic} \mathrm{orogenic} \mathrm{proc-}$ esses of Mongolia-Okhotsk or evidence from field investigations into deformation of the Mohe area, NE China. Jour Geosci Res NE Asia, 1999, 2(2): 172 178

19 李锦轶, 和政军, 莫申国, 等. 大兴安岭北部绣峰组下部砾岩的 形成时代及其大地构造意义. 地质通报, 2004. 23(2): 120 129

20 李锦轶, 莫申国, 和政军, 等. 大兴安岭北段地壳左行走滑运动
的时代及其对中国东北及邻区中生代以来地壳构造演化重建的 制约. 地学前缘, 2004, 11(3): 157 167

21 和政军, 李锦轶, 莫申国, 等. 漠河前陆盆地砂岩岩石地球化学 的构造背景和物源区分析. 中国科学, D辑, 2003, 33(12): 1219 1226[摘要] [PDF]

22 Parfenov L M, Popeko L I, Tomurtogoo O. Problems of tectonics of the Mongolia-Okhotsk orogenic belt. Geol of Pac Ocean, 2001, 16: $797 \sim 830$

23 Сорокин А А, Кудряшоь Н М, Ли Цзиньи. U-Pb Геохронология гранитоидов Октябрьского комплекса Мамьынского террейна (Приамурье). Тихоокеанская Геология, 2004, 23(5): 54 67

24 Sorokin A A, Kudryashov N M, Sorokin A P. Fragment of Paleozoic active margins at the southern periphery of the Mongolia-Okhotsk foldbelt: evidence from the northeastern Argun terrane, Amur River region. Doklady Earth Sciences, 2002, 387A: 1038 1042

25 Salnikova E B, Sergeev S A, Kotov A B, et al. U-Pb zircon dating of granulite metamorphism in the Sludyanskiy Complex, eastern Siberia. Gondwana Res, 2000, 1: 195 205

26 宋彪, 李锦轶, 牛宝贵, 等. 黑龙江省东部麻山群黑云斜长片麻 岩中锆石的年龄及其地质意义. 地球学报, 1997, 18(3): 306 312

27 Wilde S A, Zhang X Z, Wu F Y. Extension of newly identified $500 \mathrm{Ma}$ metamorphic terrain in Northeast China: further $\mathrm{U}-\mathrm{Pb}$ SHRIMP dating of the Mashan Complex, Heilongjiang Province, China. Tectonophysics, 2000, 328: 115 130 [DOI]

28 Wilde S A, 吴福元, 张兴洲. 中国东北麻山杂岩晚泛非期变质 的锆石年龄证据及全球大陆再造意义. 地球化学, 2001, 30(1): $35 \sim 50$

29 Wilde S A, Wu F Y, Zhang X Z. Late Pan-African magmatism in northeastern China: SHRIMP U-Pb zircon evidence from granitoids in the Jiamusi Massif. Precambrian Reseach, 2003, 122: 311 327[DOI]

30 吴福元, Wilde S A, 孙德有. 佳木斯地块片麻状花岗岩的锆石 离子探针 $\mathrm{U}-\mathrm{Pb}$ 年龄. 岩石学报, 2001, 17(3): 443 452

31 唐克东. 中朝陆台北侧褶皱带构造发展的几个问题. 现代地质, 1989, 3(2): 195 204

32 唐克东, 邵济安. 中亚褶皱区构造演化问题一一俄罗斯学者近 年研究成果评价. 现代地质, 1997, 11(1): 21 28

33 黑龙江省地质矿产局. 黑龙江省区域地质志. 北京: 地质出版 社, 1993. 5 25

34 苗来成, 范蔚茗, 张福勤, 等. 小兴安岭西北部新开岭-科洛杂 岩锆石SHRIMP年代学研究及其意义. 科学通报, 2003，48(22): 2315 2323[摘要] [PDF]

35 Попек Л И, Натальин Б А, Белева Г В, идр. Палеобиогеографическая зональность Палеозояи Геодинамика Юга Дальнего Востока России. Тихоокеанская Геология, 1993, 5: 19 30

36 Barbarin B. A review of the relationships between granitoid types, 
their origins and their geodynamic environments. Lithos, 1999, 46: 605 626[DOI]

37 Barbarin B. Granitoids main petrogenetic classifications in relation to origin and tectonic setting. Geol J, 1990, 25: 227 238

38 Streckeisen, A L. Classification of the common igneous rocks by means of their chemical composition: a provisional attempt. Neues Jahrbuch fur Mineralogie, Monatshefte, 1976, 1: 1 15

39 Peccerillo A, Taylor S R. Geochemistry of Eocene calc-alkaline volcanic rocks from the Kastamonu area, northern Turkey. Contrib Mineral Petrol, 1976, 58: 68 81

40 Boynton W V. Cosmochemistry of the rare earth elements: meteorite studies. In: Henderson P, ed. Rare Earth Element Geochemistry. Elsevier: 1984, 2: 63 114

41 Martin H. Adakitic magmas: modern analogues of Archean granitoids. Lithos, 1999, 46: 411 429[DOI]

42 Atherton M P, Petford N. Generation of sodium-rich magmas from newly underplated basaltic crust. Nature, 1993, 362: 144 146[DOI]

43 Zen E A. Phase relations of peralumious granitic rock and their petrogenetic implications. Ann Rew Earth Planet Sci, 1988, 16: 21 51[DOI]

44 Liegeois J P, Navez J, Hertogen J, et al. Contrasting origin of post-collisional high $\mathrm{K}$ calc-alkaline and shoshonitic versus alkaline and peralkaline granitoids. The use of sliding normalization. Lithos, 1998, 45: 1 28[DOI]

45 Taylor S R, McLennan S M. The Continental Crust: Its Composition and Evolution. Oxford: Blackwell Scientific Publications, 1985. 54 372

46 Poli G, Ghezzo C, Conticelli S. Geochemistry of granitic rocks from the Hercynian Sardinia-Corsica batholith: implication for magma genesis. Lithos, 1989, 23: 247 266 [DOI]

47 Nelson D R. Compilation of SHRIMP U-Pb Geochronology Data. Perth: Geological Survey of Western Australia Record, 1999, 189

48 Williams I S. U-Th-Pb geochronology by ion microprobe. Rew Econ Geol, 1998, 7: 1 35

49 Claesson S, Vetrin V, Bayanova $\mathrm{T}$, et al. U-Pb zircon age from a Devonian carbonatite dyke, Kola peninsula, Russia: a record of geological evolution from the Archaean to the palaeozoic. Lithos, 2000, 51(1-2): 95 108[DOI]

50 Pither W S. Granite type and tectonic environment. In: Hsu K, ed. Mountain Building Processes. London: Academic Press, 1983.
$19 \sim 40$

51 Pearce J A, Harris N B W, Tindle A G. Trace element discrimination diagrams for the tectonic interpretation of granitic rocks. Petrol, 1984, 25: 956 983

52 Harris N B W, Pearce J A, Tindle A G. Geochemical characteristics of collision-zone magmatism. In: Coward M P, Ries A C, eds. Collision Tectonics. Geol Soc Spec Publ, 1986. 19: 67 81

53 Liegeois J P. Some words on the post-collisional magmatism. Lithos, 1998, 45: XV XVII[DOI]

54 Sylvester P J. Post-collision strongly peraluminous granites. Lithos, 1998, 45: 29 44[DOI]

55 Searle M P, Parrish R R, Hodges K V, et al. Shisha Pangma leucogranite. South Tibetan Himalaya: field relations. Geochemistry, age, origin and emplacement. J Geol, 1997, 105: 295 317

56 Kuster D, Harms U. Post-collisional potassic granitoids from the southern and northwestern parts of the late Neo-proterozoic East African Orogen: A review. Lithos, 1998, 45: 177 195[DOI]

57 Ferre E C, Caby R, Peucat J J, et al. Pan-African post-collisional, ferro-potassic granite and quarts-monzonite plutons of Eastern Nigeria. Lithos, 1998, 45: 255 279[DOI]

58 Batchelor R A, Bowden V P. Petrogenetic interpretation of granitoid rock series using multicationic parameters. Chem Geol, 1985, 48(1): 43 55[DOI]

59 Pearce J A, Harris N B W, Tindle A G. Trace element discrimination diagrams for the tectonic interpretation of granitic rock. J Petrol, 1984, 25(4): 956 983

60 刘敦一, 简平, 张旗, 等. 内蒙古图林凯蛇绿岩中埃达克岩 SHRIMP 测年: 早古生代洋壳消减的证据, 地质学报, 2003, 77(3): 317 327

61 Tang K D. Tectonic development of Paleozoic fold belts at the north margin of the Sino-Korean craton. Tectonics, 1990, 9(2): 249 260

62 邵济安, 洪大卫, 张履桥. 内蒙古火成岩 $\mathrm{Sr}-\mathrm{Nd}$ 同位素特征及成 因. 地质通报, 2002, 21(12): 817 822

63 李双林, 迟效国, 戚长谋. 中国满洲里-绥芬河地学断面构造地 球化学层与构造演化. 地质地球化学, 1996, (6): 45 52

64 赵一鸣, 毕承思, 刍晓秋, 等. 黑龙江多宝山、铜山大型斑岩铜 (钼)矿床中辉钼矿的铼-锇同位素年龄. 地球学报, 1997, 18(1): $61 \sim 67$

(2005-01-07 收稿, 2005-07-07 收修改稿) 